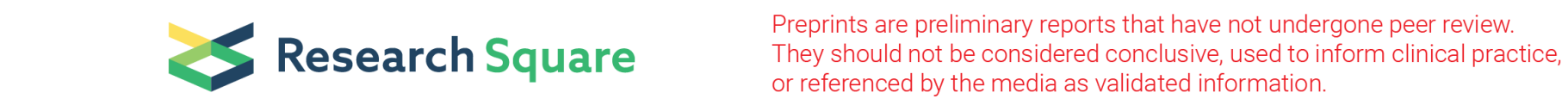

\title{
Effect of Metal Oxide Nanoparticles on Plant Enzymatic Activities Under Drought
}

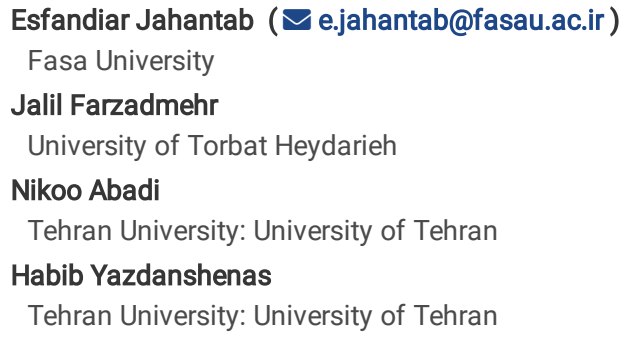

\section{Research Article}

Keywords: Drought stress, Field capacity, Foliar spray, Plant performance

Posted Date: June 30th, 2021

DOI: https://doi.org/10.21203/rs.3.rs-664294/v1

License: () (1) This work is licensed under a Creative Commons Attribution 4.0 International License. Read Full License 


\section{Abstract}

The aim of this work was to study the effect of metal oxide nanoparticles (MO NPs) on enzymatic activities (EAs) of two main plant life forms under drought stress (DS). Foliar spray of silver oxide (AgO), iron oxide (FeO), zinc oxide (ZnO) and cadmium oxide (CdO) at levels of 30,60, 90 and 120 mg. $^{-1}$ were used on aerial parts of forb Sanguisorba officinalis L. and grass Agropyron cristatum (L.) Gaertn. under DS levels of 25-100\% field capacity (FC). Glutathione reductase (GR), catalase (CAT), peroxidase (POD) and superoxide dismutase (SOD) were measured after two weeks of the experiment. The results indicate that the EAs changes varied depending on the plant life form, levels of DS, type and levels of NPs. Overall, application of $30-60 \mathrm{mg} . \mathrm{L}^{-1} \mathrm{MO}$ NPs under $25-50 \% \mathrm{FC}$ significantly reduced EAs, especially in forb $(P<0.001)$. Higher concentration of MO NPs significantly increase EAs. A decrease in CAT (20.90\%, $18.80 \%)$, POD $(21.30 \%, 17.67 \%)$ and SOD $(23.14 \%, 16.88 \%)$ was observed under levels of $60 \mathrm{mg}^{-1} \mathrm{I}^{-1}$ of ZnO NPs under $25-50 \% \mathrm{FC}$ in forb and grass, respectively. High concentration of CdO NPs $\left(90-120 \mathrm{mg}^{-1} \mathrm{I}^{-1}\right)$ caused by increase (max= $\left.24.0 \%\right)$ in EAs in both life forms under $25 \% \mathrm{FC}$.

\section{Introduction}

Today, metal oxide nanoparticles (MO NPs) have received much attention because of their effect on environmental biology (Baysal and Sayg in 2018; Rajput et al. 2018). MO NPs directly/indirectly influence the live organisms (Cheng 2003; Peng et al. 2016) and have great potential in agriculture as a means to deliver micronutrients to plants for increasing yield (Elmer et al. 2018). On one hand, to improve performance, it is imperative that we enhance plant drought tolerance (Ye et al. 2016). Among the availbe methods to improve the physiological condition of plants under stress, the use of MO NPs is a new method that has been used many times. In fact, MO NPs application is considered one of the effective methods for increasing plant resistance and biomass under drought stress (DS) by regulating their enzymatic activities (EAs). Also, proper use of MO NPs may lead to the maintenance/improvement of plants performance under DS.

Among the all enzymes, Glutathione reductase (GR), superoxide dismutase (SOD), catalase (CAT), peroxidase (POD) are the most important (Elmer et al. 2018) that play an important role against stress (Peyvandi et al. 2011; Parveen and Rao 2015; Ye et al. 2016; Trivedi et al. 2020). The plant's response to MO NPs varies according to the environmental factors. Since, different negative or positive results have been reported on the effect of MO NPs on EAs (Nair et al., 2011; Rajput et al., 2018; Akinyemi et al. 2017).

Among all the MO NPs, silver (Ag), iron (Fe), zinc (Zn), and cadmium (Cd) NPs have been widely used. Ag are prominent and are widely used in a growing number of applications (Ragam and Mathew 2020; Yu et al., 2013). Many studies have reported negative (Neal 2008; Bradford et al. 2009; Coleman et al. 2011) or positive (Yin et al. 2012; Parveen and Rao 2015) effects of AgNPs on EA. Fe also, is an essential nutrient for all organisms and plays a major role in plant EA and performance ( Miller et al., 1995; Mimmo et al., 2014; Sánchez-Alcalá et al., 2014). Fe components (i.e. FeO NPs) are auxiliary to over 140 enzymes that accelerate biochemical reactions. However, limited research has been done on the effects of iron oxide nanoparticles (FeO NPs) on plant EA (Peyvandi et al. 2011)

Moreover, Zn is a micronutrient that plays an important physiological role in plants (Dang et al. 2010; Ali et al. 2019; Shahzad et al. 2019). Zn NPs can easily penetrate into the plant cell and play an essential role in some cellular functions and metabolism in plant (Clarkson 1996; López-Millán et al. 2005; Dang et al. 2010; Jayarambabu et al. 2015). ZnO NPs are being widely used in numerous applications (Shahzad et al. 2019). Both negative and positive effects have been reported in EA by ZnO NPs application (Hernandez-Viezcas et al. 2011; Rao and Shekhawat 2014; Wang et al. 2016, 2019; Abdel Latef et al. 2017; Khan et al. 2019). Furthermore, $\mathrm{Cd}$ is a metal that is released into the nature and affect live organisms (Bayçu et al. 2017; Khan et al. 2019). However, in some studies it is shown that CdO NPs significantly changes plant's EA (Guan et al. 2009; Manara 2012).

Although there are some reports about the $\mathrm{MO}$ effects on the physiological characteristics of plants, but, there is no detailed information on the effect of $\mathrm{MO}$ NPs on EAs of different plant life forms under DS. Hence, the purpose of this study was to investigate the effect of AgO, FeO, ZnO and CdO NPs on GR, CAT, POD and SOD in forb Sanguisorba officinalis and grass Agropyron cristatum under DS. The results of this study can be used to determine the effective levels of MO NPs to improve production in grasses or forbes under DS.

\section{Methods}

The research was carried out using plots in a loamy soil (depth $=30 \mathrm{~cm}, \mathrm{pH}=7.4 \pm 0.5 ; \mathrm{OM}=1.2 \pm 0.35$ ) on 18 May 2018 at Agricultural and Natural Resources Research and Education Center, Tehran, Iran (3776166.13 m N; 384363.39 m E).

\subsection{Experiment}

A field experiment was conducted in a randomized complete block design under 4 levels of MO NPs and DS with 4 replications. Seeds (PLS=0.98) of Sanguisorba officinalis L. and Agropyron cristatum (L.) Gaertn were obtained from the gene bank of the Institute of Forests and Rangelands Research and were analyzed for the germination test in the laboratory using standard test method. Numbers of 10 seeds of each species was cultivated in $1.5 \mathrm{~m}^{2}$ plots at depth of $1-2 \mathrm{~cm}$. Plots were irrigated to field capacity (FC). After 40 days, plots were prepared for applying the treatments. Irrigation was considered as variable for plots at $25 \%$ of Field capacity (FC), $50 \%$ of FC, $75 \%$ of FC, and $100 \%$ FC (control). Then, after a week, samples were prepared for applying the MO NPs treatments.

\subsection{MO NPs preparation}

Silver oxide nanoparticles (AgO NPs; particle size $=50 \mathrm{~nm}$ ), iron oxide nanoparticles (FeO NPs; particle size $=<50 \mathrm{~nm}$ ), zinc oxide nanoparticles (ZnO NPs; particle size $=20 \mathrm{~nm}$ ), cadmium oxide nanoparticles (CdO NPs; particle size $=<50 \mathrm{~nm}$; purity of $99.8 \%$ ) was purchased from Sigma Co. Previous 
characterization showed that CdO NPs have regular spherical shape and uniform size, with an average size of $50 \mathrm{~nm}$ (Aldwayyan et al. 2013); ZnO NPs were composed of homogeneous spherical particles that were single crystals with an average size of $20 \pm 5 \mathrm{~nm}$ (Fallah et al. 2017); AgO NPs have a spherical shape and an average size of $50 \mathrm{~nm}$ (Bamdad et al. 2018); FeO NPs look like a honeycomb and average size of $40-50$ nm with smooth surface, but is nununiform (Srinivasarao et al. 2012). Therefore, confirming the seller's claim regarding MO NPs size, the research was conducted (Kim et al. 2011). MO NPs were used without any pre-treatment.

MO NPs concentrations were selected based on literatures (Mahil and Kumar 2019). MO NPs solutions were prepared using deionized water and then mechanical stirrer and ultra-sonicator (Wang et al. 2011). The required soluble concentrates were prepared adding $0.03,0.06,0.09$ and $0.12 \mathrm{~g}$ of NPs powder per one liter of deionized water. Samples were placed in an ultrasonic homogenizer for $30 \mathrm{~min}$ to create a homogenous suspension. Before using the solution, an electromagnetic stirrer was used to prevent the accumulation of particles. ICP-AES spectrometer was used to verify the nominal values of MO NPs. Analytical procedures were based on criteria of limits of detection and quantification (LOD/LOQ), linearity, sensitivity, recovery, and precision using the standard deviation of the blank signal multiplied by three and six, respectively. A 6-point calibration curve was prepared for each metal and comparing with the nominal concentrations, the measured metal concentrations in the prepared solutions showed good accuracy and statistical analysis confirmed no significant differences between the nominal and measured concentrations of metals. The ICP-AES spectrometer parameters and details of calibration curves described by Pokorska-Niewiada et al. (2018). Table 1 shows the detection and quantification limits and actual values of MO NPs in solution (30 mg.L ${ }^{-1}$ ).

Table 1 Detection and quantification limits and actual concentration of MO NPs.

\begin{tabular}{|lllllll|}
\hline \multirow{2}{*}{ Analyte } & \multicolumn{2}{l}{ Concentration $\left(\mathrm{mg} . \mathrm{L}^{-1}\right)$} & \multicolumn{4}{c|}{ Detection and quantification limits $\left(\mu \mathrm{g} . \mathrm{L}^{-1}\right)$} \\
\cline { 2 - 7 } & Actual & Sig. & LOD & LOQ & Linear range & $\mathrm{R}^{2}$ \\
ZnO & $29.08 .0 \pm 1.1$ & $0.998^{\mathrm{ns}}$ & 0.45 & 1.57 & $1.75-30000$ & 0.994 \\
$\mathrm{AgO}$ & $29.00 \pm 0.8$ & $0.996^{\mathrm{ns}}$ & 0.67 & 1.78 & $3.75-32000$ & 0.992 \\
$\mathrm{FeO}$ & $27.90 \pm 2.2$ & $0.860^{\mathrm{ns}}$ & 0.54 & 1.64 & $2.5-34000$ & 0.989 \\
CdO & $25.80 \pm 3.3$ & $0.614^{\mathrm{ns}}$ & 1.06 & 3.85 & $4.20-42000$ & 0.982 \\
\hline
\end{tabular}

LOF= Limit of Detection, LOQ= Limit of quantification

\subsection{Using MO NPs}

Foliar spray of MO NPs was performed on plants aerial parts under stress in three times in three weeks (Hong et al. 2016) at levels of $120,90,60,30$ and 0 $\mathrm{mg} \cdot \mathrm{L}^{-1}$. In order to prevent the sunburn of the leaves, MO NPs spray was applied to full foliage wetting at evening. Plants were harvested two weeks after the third stage of MO NPs spraying for EA measurement. Moreover, SPAD meter \{SPAD-502, Konica-Minolta, Tokyo, Japan\} was used for determination of the leaf chlorophyll concentration. Relative water content (RWC) was also measured for samples(Turner 1981).

\subsection{Plant EAs measurent}

Fresh leaves of the 4 plants were taken at random from each plot before flowering at vegetative growth time. Samples were immediately frozen. Then, frozen leaves were ground to a fine powder with liquid nitrogen and extracted with ice-cold $50 \mathrm{nM}$ phosphate buffer under neutral acidity condition (Meloni et al. 2003). CAT, SOD, GR and POD activity were measured using the methods described by Dazy et al. (2008), Giannopolitis and Ries (1977), Cribb et al. (1989), and Chance and Maehly (1955), respectively.

\subsection{Data analysis}

Two-way analysis of variance and compound analysis were performed to compare the measured factors. The data was then ranked and compared by Duncan's multiple range test (MRT) at the $5 \%$ level of error in SPSS v.17.01 software. Also, all graphs were drawn in Excel 2010 software.

\section{Results}

The following table shows the statistical analysis of the percentage of change in EAs and chlorophyll and relative water content in the two species by application of MO NPs under DS (Table 2). The effect of factors individually and in combination has caused a significant change in the evaluated characteristics $(P<0.001)$.

Table 2 Effect of types/levels of MO NPs, drought stress and their combined effect on physiological properties and EAs in two forb and grass studied. 


\begin{tabular}{|c|c|c|c|c|c|c|c|c|c|c|c|c|c|}
\hline \multirow[t]{2}{*}{ Source/Factor } & \multirow[t]{2}{*}{ df } & \multicolumn{2}{|l|}{ RWC } & \multicolumn{2}{|l|}{ Chlo } & \multicolumn{2}{|l|}{ GR } & \multicolumn{2}{|l|}{ CAT } & \multicolumn{2}{|l|}{ SOD } & \multicolumn{2}{|l|}{ POD } \\
\hline & & MS & $\mathrm{F}$ & MS & $\mathrm{F}$ & MS & $\mathrm{F}$ & MS & $\mathrm{F}$ & MS & $\mathrm{F}$ & MS & $\mathrm{F}$ \\
\hline Sp & 1 & 4.8 & $3.4^{\star \star}$ & 75.8 & $41.1^{\star \star}$ & 339.5 & $40.123^{\star \star}$ & 370.7 & $46.570^{\star \star}$ & 265.5 & $36.9^{\star \star}$ & 297.9 & $37.8^{\star \star}$ \\
\hline WS & 3 & 29.1 & $27.78^{\star \star}$ & 41.4 & $22.4^{* *}$ & 90.2 & $10.660^{\star *}$ & 69.3 & $8.710^{\star *}$ & 81.2 & $11.2^{\star \star}$ & 84.681 & $10.73^{\star \star}$ \\
\hline MO Ns & 3 & 7368.0 & $7027.1^{\star \star}$ & 4101.5 & $2224.1^{\star \star}$ & 9232.4 & $1090.9^{\star \star}$ & 9655 & $1212.9^{\star \star}$ & 9268.2 & $1288.7^{\star \star}$ & 9967.2 & $1265.6^{\star \star}$ \\
\hline MO NPs L & 3 & 4077.1 & $3888.4^{* *}$ & 7536.3 & $4086.6^{\star \star}$ & 12356.9 & $1460.1^{* \star}$ & 12957 & $1627.7^{\star \star}$ & 12344 & $1716.6^{* *}$ & 13350 & $1695.2^{\star \star}$ \\
\hline$S p * W S$ & 3 & 72.9 & $69.5^{\star \star}$ & 65.890 & $35.7^{\star \star}$ & 43.3 & $5.126^{\star *}$ & 62.817 & $7.891^{\star \star}$ & 48.8 & $6.8^{\star \star}$ & 52.1 & $6.61^{\star *}$ \\
\hline $\begin{array}{l}\mathrm{Sp} \text { * MO NPs } \\
\end{array}$ & 3 & 50.1 & $47.7^{* \star}$ & 108.1 & $58.6^{* *}$ & 890.5 & $105.2^{* \star}$ & 956.0 & $120.1^{\star *}$ & 1012.2 & $140.7^{* \star}$ & 1071.9 & $136.1^{\star *}$ \\
\hline $\mathrm{Sp}$ * MO NPs & 3 & 32.5 & $31.1^{\star \star}$ & 233.5 & $126.6^{\star *}$ & 110.0 & $13.001^{\star \star}$ & 113.3 & $14.2^{\star \star}$ & 139.3 & $19.3^{\star \star}$ & 148.8 & $18.8^{\star \star}$ \\
\hline $\begin{array}{l}\text { WS * MO NPs } \\
L\end{array}$ & 9 & 67.2 & $64.1^{* *}$ & 78.4 & $42.5^{* \star}$ & 456.9 & $53.99^{\star \star}$ & 508.4 & $63.8^{\star \star}$ & 458.2 & $63.7^{\star *}$ & 506.9 & $64.3^{\star \star}$ \\
\hline WS * MO NPs & 9 & 76.9 & $73.3^{\star \star}$ & 70.4 & $38.2^{\star \star}$ & 88.5 & $10.46^{\star *}$ & 92.7 & $11.6^{\star \star}$ & 85.0 & $11.8^{\star \star}$ & 91.8 & $11.6^{\star *}$ \\
\hline $\begin{array}{l}\text { MO NPs L* } \\
\text { MO NPs }\end{array}$ & 9 & 1108.2 & $1056.9^{\star *}$ & 1156.4 & $627.1^{\star *}$ & 498.0 & $58.85^{\star *}$ & 556.0 & $69.8^{* *}$ & 520.4 & $72.3^{\star \star}$ & 568.9 & 72. $1^{\text {** }}$ \\
\hline $\begin{array}{l}S P * W S * M O \\
\text { NPs L }\end{array}$ & 9 & 10.6 & $10.1^{\star *}$ & 17.5 & $9.5^{\star *}$ & $20.2^{*}$ & $2.38^{\star \star}$ & 24.1 & $3.0^{*}$ & 22.8 & $3.2^{*}$ & 23.8 & $3.0^{*}$ \\
\hline $\begin{array}{l}\mathrm{SP} * \mathrm{WS} * \mathrm{MO} \\
\mathrm{NPS}\end{array}$ & 9 & 16.0 & $15.3^{\star \star}$ & 12.2 & $6.5^{* *}$ & 43.9 & $5.14^{\star \star}$ & 37.1 & $4.6^{* *}$ & 37.1 & $5.2^{\star *}$ & 38.3 & $4.8^{\star \star}$ \\
\hline $\begin{array}{l}\text { SP* MO NPs } \\
L^{*} \text { MO NPs }\end{array}$ & 9 & 7.6 & $7.3^{* *}$ & 33.6 & $18.2^{* \star}$ & 121.5 & $14.32^{* *}$ & 134.2 & $16.8^{\star \star}$ & 128.7 & $17.9^{* \star}$ & 143.0 & $18.1^{\star *}$ \\
\hline $\begin{array}{l}\text { WS*MO NPs } \\
\text { L*MO NPs }\end{array}$ & 27 & 30.5 & $29.1^{\star \star}$ & 35.3 & $19.17^{\star \star}$ & 96.9 & $11.44^{\star \star}$ & 93.6 & $11.7^{\star \star}$ & 95.9 & $13.3^{\star \star}$ & 100.9 & $12.8^{\star \star}$ \\
\hline $\begin{array}{l}\text { SP*WS*MO } \\
\text { NPs L*MO } \\
\text { NPs }\end{array}$ & 27 & 12.16 & $11.6^{* *}$ & 13.6 & $7.423^{\star *}$ & 24.0 & $2.83^{*}$ & 23.3 & $2.9^{*}$ & 21.85 & $3.04^{\star *}$ & 23.0 & $2.9^{*}$ \\
\hline
\end{tabular}

WS=Water stress, Sp=Specie, MO NPs= Metal oxide nanoparticles, MO NP Ls= Metal oxide nanoparticles Levels, MS=Mean Square, Chlo= Chlorophyll, $\mathrm{GR}=\mathrm{Glutathione}$ reductase, $\mathrm{CAT}=$ catalase, $\mathrm{POD}=$ peroxidase, $\mathrm{SOD}=$ superoxide dismutase, $\mathrm{RWC}=$ relative water content.

Preliminary results of morphophysiological characteristics of plants under stress showed that the application of MO NPs significantly changed the photosynthetic and moisture content of the leaves (Table 2). Application of low levels of MO NPs under DS had a relative improvement in leaf RWC compared to the control. Generally, using $60 \mathrm{mg}$. $\mathrm{L}^{-1} \mathrm{ZnO}$ under $25 \% \mathrm{FC}$ significantly improves RWC of the leaves.

EAs significantly changed under different types and concentration of MO NPs in two species under DS (Fig. 2: A-C). Firstly, there was a significant difference in EAs changes in between tow species $(P<0.001)$. Different levels of DS also influenced EAs (Fig. 2: D) It seems that grasses and forbs have a different potential to control their EAs under DS. All MO NPs used in this research showed a significant effect on GR activity in forb $S$. officinalis and grass $A$. cristatum. The

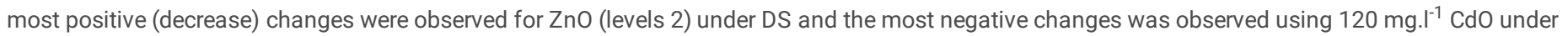
$25 \% \mathrm{FC}$. However, A. cristatum showed lower changes in GR than S. officinalis. Therefore, EAs changes depond directly on the plant species (Kanwar et al. 2019).

Moreover, CAT showed significant changes under MO NPs and DS levels. The highest changes occurred under different levels of ZnO and CdO, respectively. The CAT changes of $A$. cristatum, which was, of course, less pronounced than that of in S. officinalis. Application $120 \mathrm{mg} . \mathrm{I}^{-1} \mathrm{CdO}$ showed the most negative (increase) effect on EAs i.e. CAT under drought in both species (Fig. 2; A).

SOD activity also showed notable changes under MO NPs application and DS. The lowest SOD activity was observed under ZnO $\left(\mathrm{L}_{2}\right)$ in both $S$. officinalis and A. cristatum. The most negative effect was observed under $120 \mathrm{mg.l}^{-1} \mathrm{CdO}$ and severe drought of $25 \% \mathrm{FC}$ (Fig. 2 and 3). Generally, using $30-60$ mg. $\mathrm{I}^{-1} \mathrm{MO}$ NPs particularly $\mathrm{ZnO}$ caused a significant reduction in SOD activity in grass A. cristatum and forb $S$. officinalis.

Furthermore, POD showed significant changes under MO NPs and DS in which lower levels of MO NPs and DS had positive effects on increasing plant drought tolerance and led to decreased POD activity in S. officinalis and A. cristatum (Fig. 2-3). Application of 60 mg. $\mathrm{I}^{-1} \mathrm{MO}$ NPs had the most effect on POD

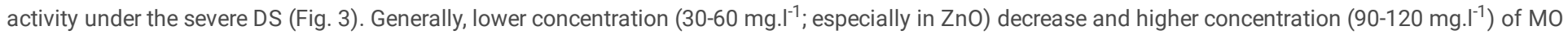
NPs increase POD activity in both species DS.

Generally, EAs changes varied depending on the plant species, type and concentration of MO NPs, and levels of DS. The most changes in EAs were related to forb S. officinalis. Low concentration $\left(<60 \mathrm{mg}^{-\mathrm{I}^{-1}}\right)$ of $\mathrm{AgO}, \mathrm{FeO}, \mathrm{ZnO}$ and $\mathrm{CdO} \mathrm{NPs}$ had a positive effect on the reduction of EAs. And higher concentration (90-

Page $4 / 12$ 
$120 \mathrm{mg}^{-1} \mathrm{I}^{-1}$, especially $\mathrm{CdO}$ ) causes toxicity and increased EAs in both forb S. officinalis and grass A. cristatum under DS.

\section{Discussion}

This study described the physiological properties of two plant forms including grass and broadleaf using different concentrations of MO Ns under drought conditions. The first change involved a relative improvement in the moisture content of both plant forms. This improvement showed the greatest change in medium stresses and medium concentrations of nanoparticles. It seems that application of optimal amount of nanoparticles by controlling physiological activities and controlling moisture exchange in plant cell membranes helps maintain moisture in plant organs (Chakhchar et al. 2016).

RWC in plant organs is the result of the adaptation mechanism induction of investigated plants at drought conditions (Taran et al. 2017). However, the most change of RWC was observed under application of $\mathrm{ZnO}\left(60 \mathrm{mg} . \mathrm{I}^{-1}\right)$ especially under severe drought in both studies grass and forb. It has been reported that foliar selenium application significantly lowered osmotic potential (13\%) and increased RWC (Nawaz et al. 2015). In another study, also, RWC of Phaseolus vulgaris leaves was significantly affected under $\mathrm{CeO} 2$ sprayed and the most RWC (80\%) was observed under $250 \mathrm{mg} \mathrm{L-1} \mathrm{MO} \mathrm{application} \mathrm{and} \mathrm{higher} \mathrm{levels}$ significantly decreased RWC of plant leaves (Salehi et al. 2018). Another study also indicated that Zn NPs decreased the negative effect of drought effects and increased RWC in wheat leaves (Taran et al. 2017). In fact, Zn improves the plant response under environmental stress (Khan et al. 2019). Therefore, MO NPs may have a positive effect on maintaining the water content of plant leaves.

Our results suggested that GR activity controlled and reduced under low concentration of MO NPs and levels of DS in both grass and forb. But higher levels of $\mathrm{AgO}, \mathrm{FeO}, \mathrm{ZnO}$ and particularly CdO NPs have negative effects and increase GR activity. Generally, GR activity will increase under stress. However, previous study indicated that ZnO NPs (100 and $200 \mathrm{mM}$ ) declined GR activity by 25 and 45\% in wheat seedlings (Tripathi et al. 2017b). The GR plant chloroplasts controles physiological mechanisms, especially under DS (Yousuf et al. 2012) and therefore showed a decrease under low concentration of MO NPs.

Moreovere, the CAT changed under the influence of type and concentration of MO NPs and as well as DS. Also, the rate of these changes was not the same between the two plant plant forms. The CAT plays an indispensable role in detoxification activity under stress (Yang et al. 2017) and could be changed by MO NPs (Du et al. 2017). A number of studies also showed that lower concentrations of Zn NPs changed the CAT activity and enhanced the plant defense system under stress (Raigond et al. 2017; Abdel-Aziz 2019; Du et al., 2017; Hernandez-Viezcas et al., 2011; Zhao et al., 2015). Another study also showed that lower concentrations of Zn NPs changed the CAT activity and indicated that the relatively low levels of NPs enhanced the plant defense system by increasing antioxidant EA in Lupine plant under stress (Abdel-Aziz 2019).

Similarly, Rao and Shekhawat (2014) disclosed that lower concentrations of ZnO hadn't significant effect on CAT but, higher concentration (>1000 mg/l) significantly increased EA in Brassica juncea (Rao and Shekhawat 2014). Such trend also was founded in the potato plant under higher levels of Zn NPs (Raigond et al. 2017). Simmilarly, using 25-200 $\mathrm{mg} \mathrm{L}^{-1} \mathrm{ZnO}$ NPs has led to a decrease in the CAT activity in cotton (Venkatachalam et al. 2017). Therefore, CAT activity may affect by MO NPs. These changes will be different deponding on the plants species, the type and concentration of MO NPs and levels of DS.

Furthermore, the metalloenzyme SOD is the most effective antioxidant intracellular enzyme that various environmental stresses often lead to increased it (Chakhchar et al. 2016). Similar to our findings, other researchers reported that high concentration of NPs significantly stimulated SOD activity in plants exposed to levels $>100 \mathrm{mg} / \mathrm{L}$ ZnO NPs (Suman et al. 2015; Tripathi et al. 2017a). These results also have been confirmed in previous researches under the DS (Mustafa et al. 2015).

Simmilar to SOD, the POD activity showed significant changeds under MONs and DSs. Similarly, Siddiqi and Husen, (2017) reported that the POD activity was remarkably inhibited by the large quantity of ZnO NPs. However, the effects of different MO NPs depend upon the type and concentration of NP that change plant performance (Kanwar et al. 2019).

Gupta et al., (2018) reported that AgNPs (10-40 ppm) application promoted the plant biomass and SOD, CAT and GR significantly decreased using 40 ppm. Also, Çatav et al., (2020) showed that higher concentration of Cd severely increased GR, POD and SOD in Triticum aestivum. Similarly, Wang et al., (2019) disclosed that CAT, POD and SOD decreased by increase Zn concentration in wheat seedlings. EAs provide protection to plants by contributing to cellular osmotic adjustment, stabilization of protein structure, scavenging of hydroxyl radicals, and regulation of cytosolic pH under stress (Çatav et al. 2020). In fact, NPs application prompts activation of plant defense mechanism to combat damage under stress and very high concentrations of nanoparticles cause oxidative stress and impair the function of plant cells(Gupta et al. 2018).

\section{Conclusion}

This study demonstrates that the changes in the physiological characteristics (EAs of RG, SOD, CAT and POD) of each plant vary depending on the type and concentration of treatment (MO NPs) and under specific conditions of DS. The highest and lowest EA changes were observed in forb $S$. officinalis and grass $A$. cristatum, respectively. Generally, positive effects (EA reduction) were observed at lower concentrations of MO NPs $\left(<60\right.$ mg..$\left.^{-1}\right)$ and resulted in plant resistance to levels of DS. Higher levels of MO NPs $\left(>60 \mathrm{mg}^{-\mathrm{I}^{-1}}\right)$ had negative effects and increased RG, SOD, CAT and POD $(P$. $<0.05)$. 30-60 mg. $\mathrm{I}^{-1}$ of ZnO NPs had the most positive effect on plants EA under different levels of DS in both forb S. officinalis and grass $A$. cristatum, respectively. MO NPs application also preserves the RWC of plant tissues under DS. Low concentration (30-60 $\mathrm{mg} \mathrm{.}^{-1}$ ) of AgO, FeO, ZnO and CdO NPs had a positive effect and increase RWC (Up to 11\%).

\section{Declarations}


The authors declare that they have no known competing financial interests that could have appeared to influence the work reported in this paper

\section{Acknowledgement}

This reseach was supported by Agricultural and Natural Resources Research and Education Center, Tehran,. The authors also thank to Dr. Farahani and Tarnian for their help during research.

\section{References}

Abdel-Aziz H (2019) Effect of Priming with Chitosan Nanoparticles on Germination, Seedling Growth and Antioxidant Enzymes of Broad Beans. Catrina: The International Journal of Environmental Sciences 18:81-86

Abdel Latef AAH, Abu Alhmad MF, Abdelfattah KE (2017) The Possible Roles of Priming with ZnO Nanoparticles in Mitigation of Salinity Stress in Lupine (Lupinus termis) Plants. Journal of Plant Growth Regulation. https://doi.org/10.1007/s00344-016-9618-x

Akinyemi AJ, Faboya OL, Olayide I, et al (2017) Effect of cadmium stress on non-enzymatic antioxidant and nitric oxide levels in two varieties of maize (Zea mays). Bulletin of environmental contamination and toxicology 98:845-849

Aldwayyan AS, Al-Jekhedab FM, Al-Noaimi M, et al (2013) Synthesis and characterization of CdO nanoparticles starting from organometalic dmphen-CdI2 complex. Int J Electrochem Sci 8:10506-10514

Ali S, Rizwan M, Noureen S, et al (2019) Combined use of biochar and zinc oxide nanoparticle foliar spray improved the plant growth and decreased the cadmium accumulation in rice (Oryza sativa L.) plant. Environmental Science and Pollution Research 26:11288-11299. https://doi.org/10.1007/s11356-01904554-y

Ameen S, Akhtar MS, Kim YS, et al (2011) Polyaniline/gallium doped ZnO heterostructure device via plasma enhanced polymerization technique: Preparation, characterization and electrical properties. Microchimica Acta 172:471-478

Bamdad K, Mohammadgani B, Dadfar F, Moradi A (2018) The effect of gold, silver and zinc oxide nanoparticles on oxidative stress parameters level in the liver, heart and lung of male mice. Journal of Fasa University of Medical Sciences 7:455-464

Bayçu G, Gevrek-Kürüm N, Moustaka J, et al (2017) Cadmium-zinc accumulation and photosystem II responses of Noccaea caerulescens to Cd and Zn exposure. Environmental Science and Pollution Research. https://doi.org/10.1007/s11356-016-8048-4

Baysal A, Sayg \in H (2018) Effect of zinc oxide nanoparticles on the trace element contents of soils. Chemistry and Ecology 34:713-726

Bradford A, Handy RD, Readman JW, et al (2009) Impact of silver nanoparticle contamination on the genetic diversity of natural bacterial assemblages in estuarine sediments. Environmental Science \& Technology 43:4530-4536

Çatav \cSükrü Serter, Genç TO, Oktay MK, Küçükakyüz K (2020) Cadmium toxicity in wheat: impacts on element contents, antioxidant enzyme activities, oxidative stress, and genotoxicity. Bulletin of Environmental Contamination and Toxicology 104:71-77

Chakhchar A, Lamaoui M, Aissam S, et al (2016) Differential physiological and antioxidative responses to drought stress and recovery among four contrasting Argania spinosa ecotypes. 9145:. https://doi.org/10.1080/17429145.2016.1148204

Chance B, Maehly AC (1955) [136] Assay of catalases and peroxidases

Chaudhuri SK, Malodia L (2017) Biosynthesis of zinc oxide nanoparticles using leaf extract of Calotropis gigantea: characterization and its evaluation on tree seedling growth in nursery stage. Applied Nanoscience 7:501-512

Cheng S (2003) Effects of heavy metals on plants and resistance mechanisms. Environmental Science and Pollution Research 10:256-264.

https://doi.org/10.1065/espr2002.11.141.2

Clarkson D (1996) Marschner H. 1995.Mineral nutrition of higher plants.second edition. 889pp. London: Academic Press, £29.95 (paperback). Annals of Botany. https://doi.org/10.1006/anbo.1996.0155

Coleman VA, Jämting ÅK, Catchpoole HJ, et al (2011) Nanoparticles and metrology: a comparison of methods for the determination of particle size distributions. In: Instrumentation, Metrology, and Standards for Nanomanufacturing, Optics, and Semiconductors V

Cribb AE, Leeder JS, Spielberg SP (1989) Use of a microplate reader in an assay of glutathione reductase using 5, 5'-dithiobis (2-nitrobenzoic acid). Analytical biochemistry 183:195-196

Dang HK, Li RQ, Sun YH, et al (2010) Absorption, accumulation and distribution of zinc in highly-yielding winter wheat. Agricultural Sciences in China. https://doi.org/10.1016/S1671-2927(09)60178-4

Dazy M, Jung V, Férard JF, Masfaraud JF (2008) Ecological recovery of vegetation on a coke-factory soil: Role of plant antioxidant enzymes and possible implications in site restoration. Chemosphere. https://doi.org/10.1016/j.chemosphere.2008.09.014

Page $6 / 12$ 
Dhoke SK, Mahajan P, Kamble R, Khanna A (2013) Effect of nanoparticles suspension on the growth of mung (Vigna radiata) seedlings by foliar spray method. Nanotechnology Development. https://doi.org/10.4081/nd.2013.e1

Du W, Tan W, Peralta-Videa JR, et al (2017) Interaction of metal oxide nanoparticles with higher terrestrial plants: Physiological and biochemical aspects. Plant Physiology and Biochemistry

Elmer W, Latorre-Roche R De, Pagano L, et al (2018) Effect of metalloid and metal oxide nanoparticles on fusarium wilt of watermelon. Plant Disease. https://doi.org/10.1094/PDIS-10-17-1621-RE

Fallah S, Ghasemi S, Rostam Nejadi A (2017) Comparison of Toxicity of Zinc Oxide Nano Particles on Growth of Fenugreek (Trigonella foenum-graceum) under Greenhouse Conditions. Journal of Plant Production Research 24:23-42

Garg N, Manchanda G (2009) ROS generation in plants: boon or bane? Plant Biosystems 143:81-96

Giannopolitis C, Ries S (1977) Superoxide Dismutases: I. Occurrence in Higher Plants. Plant Physiology. https://doi.org/10.1104/pp.59.2.309

Guan ZQ, Chai TY, Zhang YX, et al (2009) Enhancement of Cd tolerance in transgenic tobacco plants overexpressing a Cd-induced catalase cDNA.

Chemosphere. https://doi.org/10.1016/j.chemosphere.2009.04.047

Gupta SD, Agarwal A, Pradhan S (2018) Phytostimulatory effect of silver nanoparticles (AgNPs) on rice seedling growth: an insight from antioxidative enzyme activities and gene expression patterns. Ecotoxicology and Environmental Safety 161:624-633

Hernandez-Viezcas JA, Castillo-Michel H, Servin AD, et al (2011) Spectroscopic verification of zinc absorption and distribution in the desert plant Prosopis juliflora-velutina (velvet mesquite) treated with ZnO nanoparticles. Chemical Engineering Journal. https://doi.org/10.1016/j.cej.2010.12.021

Hong J, Wang L, Sun Y, et al (2016) Foliar applied nanoscale and microscale CeO2 and CuO alter cucumber (Cucumis sativus) fruit quality. Science of the Total Environment. https://doi.org/10.1016/j.scitotenv.2015.08.029

Jayarambabu N, KUMARI BS, RAO KV, Prabhu YT (2015) Beneficial role of zinc oxide nanoparticles on green crop production. International Journal of Multidisciplinary Advanced Research Trends 2:273-282

Kanwar MK, Sun S, Chu X, Zhou J (2019) Impacts of Metal and Metal Oxide Nanoparticles on Plant Growth and Productivity. In: Nanomaterials and Plant Potential. Springer, pp 379-392

Karimi N, Souri Z (2016) Antioxidant enzymes and compounds complement each other during arsenic detoxification in shoots of Isatis cappadocica Desv. Chemistry and Ecology 32:937-951

Khan MR, Rizvi TF, others (2014) Nanotechnology: scope and application in plant disease management. Plant Pathol J 13:214-231

Khan ZS, Rizwan M, Hafeez M, et al (2019) The accumulation of cadmium in wheat (Triticum aestivum) as influenced by zinc oxide nanoparticles and soil moisture conditions. Environmental Science and Pollution Research 26:19859-19870. https://doi.org/10.1007/s11356-019-05333-5

Khatun Z, Lawrence RS, Jalees M, Lawerence K (2015) Green synthesis and Anti-bacterial activity of Silver Oxide nanoparticles prepared from Pinuslongifolia leaves extract. International Journal 3:337-343

Khot LR, Sankaran S, Maja JM, et al (2012) Applications of nanomaterials in agricultural production and crop protection: A review. Crop Protection

Kim S, Kim J, Lee I (2011) Effects of Zn and ZnO nanoparticles and Zn on soil enzyme activity and bioaccumulation of Zn in Cucumis sativus. https://doi.org/10.1080/02757540.2010.529074

Loneragan JF (1975) The availability and absorption of trace elements in soil-plant systems and their relation to movement and concentrations of trace elements in plants. Academic Press, New York

López-Millán AF, Ellis DR, Grusak MA (2005) Effect of zinc and manganese supply on the activities of superoxide dismutase and carbonic anhydrase in Medicago truncatula wild type and raz mutant plants. Plant Science. https://doi.org/10.1016/j.plantsci.2004.11.018

Mahil EIT, Kumar BNA (2019) Foliar application of nanofertilizers in agricultural crops-A review. Foliarapplication of nanofertilizers in agricultural crops Areview 32:239-249

Manara A (2012) Plant Responses to Heavy Metal Toxicity

Meloni DA, Oliva MA, Martinez CA, Cambraia J (2003) Photosynthesis and activity of superoxide dismutase, peroxidase and glutathione reductase in cotton under salt stress. Environmental and Experimental Botany 49:69-76. https://doi.org/10.1016/S0098-8472(02)00058-8

Mimmo T, Del Buono D, Terzano R, et al (2014) Rhizospheric organic compounds in the soil-microorganism-plant system: Their role in iron availability. European Journal of Soil Science 
Mustafa G, Sakata K, Hossain Z, Komatsu S (2015) Proteomic study on the effects of silver nanoparticles on soybean under flooding stress. Journal of Proteomics. https://doi.org/10.1016/j.jprot.2015.03.030

Nair R, Poulose AC, Nagaoka Y, et al (2011) Uptake of FITC labeled silica nanoparticles and quantum dots by rice seedlings: Effects on seed germination and their potential as biolabels for plants. Journal of Fluorescence. https://doi.org/10.1007/s10895-011-0904-5

Nawaz F, Ahmad R, Ashraf MY, et al (2015) Ecotoxicology and Environmental Safety Effect of selenium foliar spray on physiological and biochemical processes and chemical constituents of wheat under drought stress. Ecotoxicology and Environmental Safety 113:191-200.

https://doi.org/10.1016/j.ecoenv.2014.12.003

Neal AL (2008) What can be inferred from bacterium-nanoparticle interactions about the potential consequences of environmental exposure to nanoparticles? Ecotoxicology

Parveen A, Rao S (2015) Effect of Nanosilver on Seed Germination and Seedling Growth in Pennisetum glaucum. Journal of Cluster Science. https://doi.org/10.1007/s10876-014-0728-y

Peng Y, Chen R, Yang R (2016) Analysis of heavy metals in Pseudostellaria heterophylla in Baiyi Country of Wudang District. Journal of Geochemical Exploration. https://doi.org/10.1016/j.gexplo.2016.02.011

Peyvandi M, Parande H, Mirza M (2011) Comparison of Nano Fe chelate with Fe chelate Effect on growth parameters and antioxidant enzymes activity of Ocimum basilicum

Pokorska-Niewiada K, Rajkowska-Myśliwiec M, Protasowicki M (2018) Acute lethal toxicity of heavy metals to the seeds of plants of high importance to humans. Bulletin of environmental contamination and toxicology 101:222-228

Ragam PN, Mathew B (2020) Unmodified silver nanoparticles for dual detection of dithiocarbamate fungicide and rapid degradation of water pollutants. International Journal of Environmental Science and Technology 17:1739-1752

Raigond P, Raigond B, Kaundal B, et al (2017) Effect of zinc nanoparticles on antioxidative system of potato plants. Journal of Environmental Biology. https://doi.org/10.22438/jeb/38/3/MS-209

Rajput VD, Minkina TM, Behal A, et al (2018) Effects of zinc-oxide nanoparticles on soil, plants, animals and soil organisms: A review. Environmental Nanotechnology, Monitoring and Management

Raliya R, Nair R, Chavalmane S, et al (2015) Mechanistic evaluation of translocation and physiological impact of titanium dioxide and zinc oxide nanoparticles on the tomato (Solanum lycopersicum L.) plant. Metallomics 7:1584-1594

Rao S, Shekhawat GS (2014) Toxicity of ZnO engineered nanoparticles and evaluation of their effect on growth, metabolism and tissue specific accumulation in Brassica juncea. Journal of Environmental Chemical Engineering. https://doi.org/10.1016/j.jece.2013.11.029

Salehi H, Chehregani A, Lucini L, et al (2018) Morphological, proteomic and metabolomic insight into the effect of cerium dioxide nanoparticles to Phaseolus vulgaris L. under soil or foliar application. Science of the Total Environment 616:1540-1551

Sánchez-Alcalá I, del Campillo M del carmen, Barrón V, Torrent J (2014) Evaluation of preflooding effects on iron extractability and phytoavailability in highly calcareous soil in containers. Journal of Plant Nutrition and Soil Science. https://doi.org/10.1002/jpln.201200302

Servin A, Elmer W, Mukherjee A, et al (2015) A review of the use of engineered nanomaterials to suppress plant disease and enhance crop yield. Journal of Nanoparticle Research

Shahzad K, Khan MN, Jabeen F, et al (2019) Toxicity of zinc oxide nanoparticles (ZnO-NPs) in tilapia (Oreochromis mossambicus): tissue accumulation, oxidative stress, histopathology and genotoxicity. International journal of environmental science and technology 16:1973-1984

Siddiqi KS, Husen A (2017) Plant Response to Engineered Metal Oxide Nanoparticles. Nanoscale Research Letters

Srinivasarao C, Venkateswarlu B, Lal R, et al (2012) Soil carbon sequestration and agronomic productivity of an Alfisol for a groundnut-based system in a semiarid environment in southern India. European Journal of Agronomy 43:40-48

Suman TY, Rajasree SRR, Kirubagaran R (2015) Evaluation of zinc oxide nanoparticles toxicity on marine algae Chlorella vulgaris through flow cytometric, cytotoxicity and oxidative stress analysis. Ecotoxicology and environmental safety 113:23-30

Taran N, Storozhenko V, Svietlova N, et al (2017) Effect of zinc and copper nanoparticles on drought resistance of wheat seedlings. Nanoscale research letters $12: 60$

Tripathi DK, Mishra RK, Singh S, et al (2017a) Nitric oxide ameliorates zinc oxide nanoparticles phytotoxicity in wheat seedlings: implication of the ascorbateglutathione cycle. Frontiers in plant science 8:1 
Tripathi DK, Singh S, Singh S, et al (2017b) Nitric oxide alleviates silver nanoparticles (AgNps)-induced phytotoxicity in Pisum sativum seedlings. Plant Physiology and Biochemistry. https://doi.org/10.1016/j.plaphy.2016.06.015

Trivedi VL, Nautiyal MC, Sati J, Attri DC (2020) Antioxidant enzyme activities in male and female plants of Hippophae salicifolia D. Don in different phenophases. Acta Physiologiae Plantarum 42:

Turner NC (1981) Techniques and experimental approaches for the measurement of plant water status. Plant and soil 58:339-366

Venkatachalam P, Priyanka N, Manikandan K, et al (2017) Enhanced plant growth promoting role of phycomolecules coated zinc oxide nanoparticles with P supplementation in cotton (Gossypium hirsutum L.). Plant Physiology and Biochemistry. https://doi.org/10.1016/j.plaphy.2016.09.004

Wang H, Kou X, Pei Z, et al (2011a) Physiological effects of magnetite ( Fe 304 ) nanoparticles on perennial ryegrass ( Lolium perenne L .) and pumpkin ( Cucurbita mixta ) plants. 5:30-42. https://doi.org/10.3109/17435390.2010.489206

Wang H, Kou X, Pei Z, et al (2011b) Physiological effects of magnetite (Fe304) nanoparticles on perennial ryegrass (Lolium perenne L.) and pumpkin (Cucurbita mixta) plants. Nanotoxicology. https://doi.org/10.3109/17435390.2010.489206

Wang X, Yang X, Chen S, et al (2016) Zinc oxide nanoparticles affect biomass accumulation and photosynthesis in Arabidopsis. Frontiers in Plant Science. https://doi.org/10.3389/fpls.2015.01243

Wang Z, Li H, Li X, et al (2019) Nano-ZnO priming induces salt tolerance by promoting photosynthetic carbon assimilation in wheat. Archives of Agronomy and Soil Science. https://doi.org/10.1080/03650340.2019.1663508

Yang J, Cao W, Rui Y (2017) Interactions between nanoparticles and plants: phytotoxicity and defense mechanisms. Journal of Plant Interactions 12:158169. https://doi.org/10.1080/17429145.2017.1310944

Ye J, Wang S, Deng X, et al (2016) Melatonin increased maize (Zea mays L.) seedling drought tolerance by alleviating drought-induced photosynthetic inhibition and oxidative damage. Acta physiologiae plantarum 38:48

Yin L, Colman BP, McGill BM, et al (2012) Effects of Silver Nanoparticle Exposure on Germination and Early Growth of Eleven Wetland Plants. PLoS ONE. https://doi.org/10.1371/journal.pone.0047674

Yousuf PY, Hakeem KUR, Chandna R, Ahmad P (2012) Role of glutathione reductase in plant abiotic stress. In: Abiotic Stress Responses in Plants. Springer, pp $149-158$

Yu S, Yin Y, Liu J (2013) Silver nanoparticles in the environment. Environmental Science: Processes \& Impacts 15:78-92

Zhao L, Sun Y, Hernandez-Viezcas JA, et al (2015) Monitoring the environmental effects of CeO2 and ZnO nanoparticles through the life cycle of corn (Zea mays) plants and in situ $\mu$-XRF mapping of nutrients in kernels. Environmental Science and Technology. https://doi.org/10.1021/es5060226

\section{Figures}



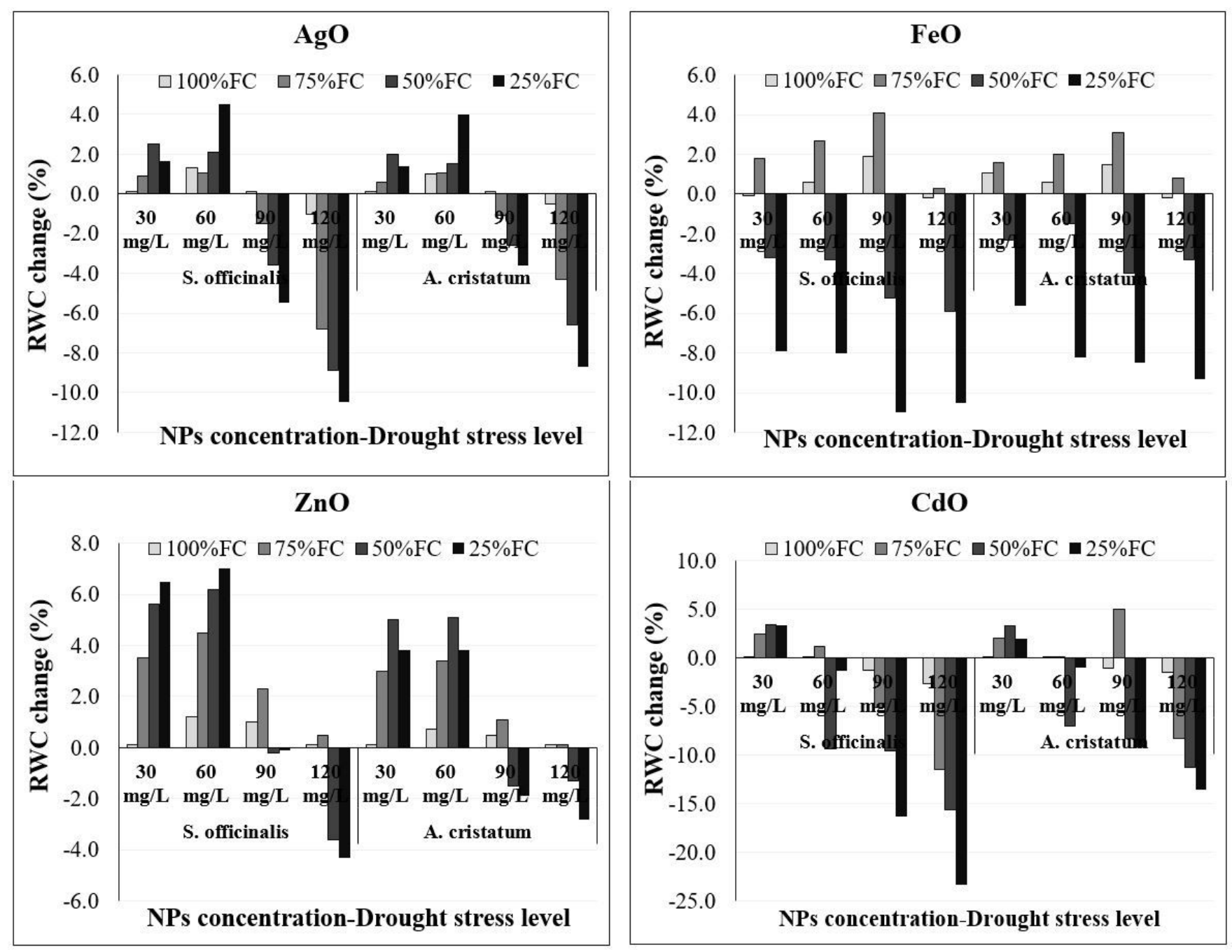

Figure 1

Percentage of changes in relative water content of leaves of S. officinalis and A. cristatum under different types/levels of MO NPs under water stress in relation to control. 

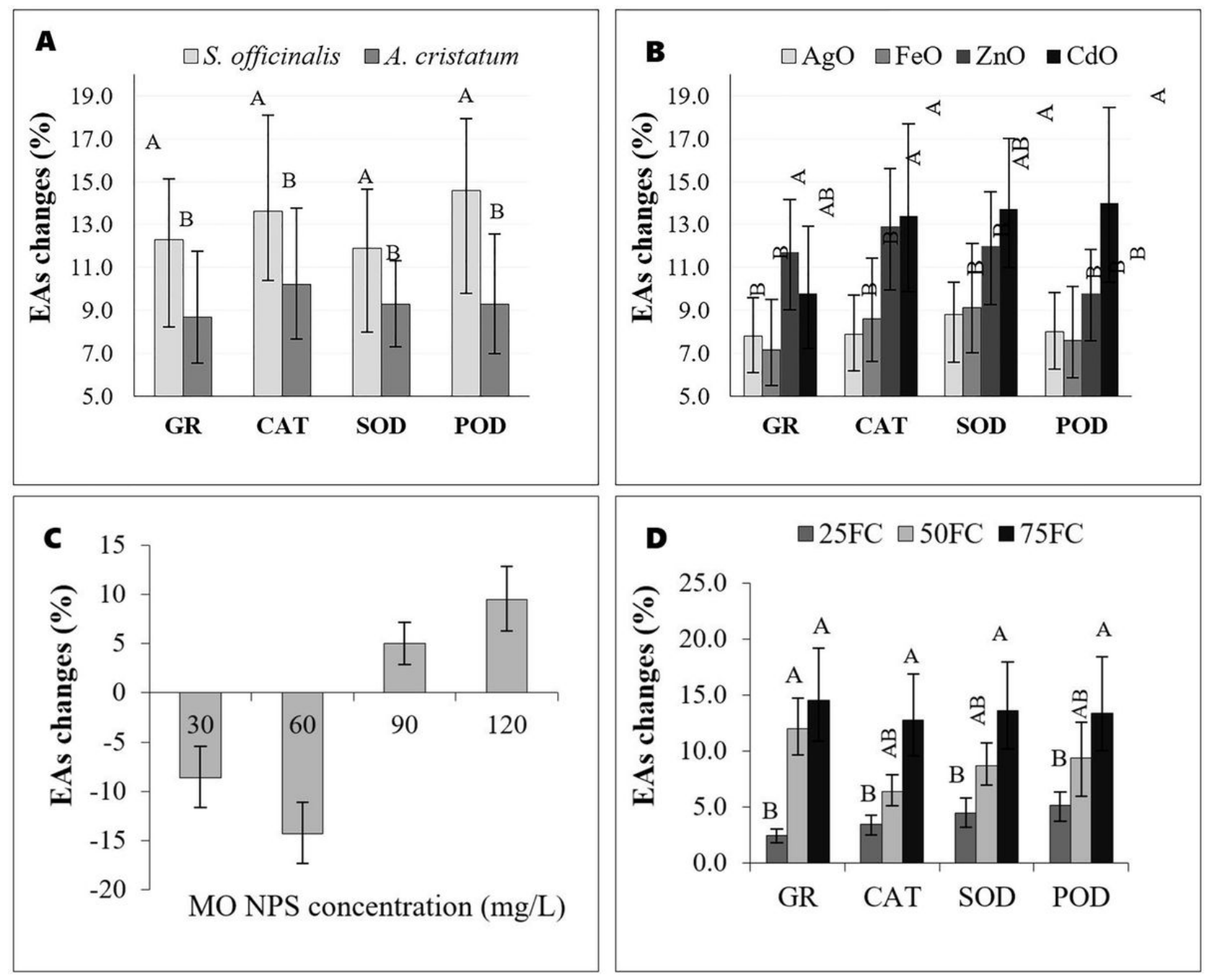

Figure 2

Percentage of changes in EAs for species (A), MO NPs type (B), MO NPs concentration (C) and for water stress levels in relation to control. 


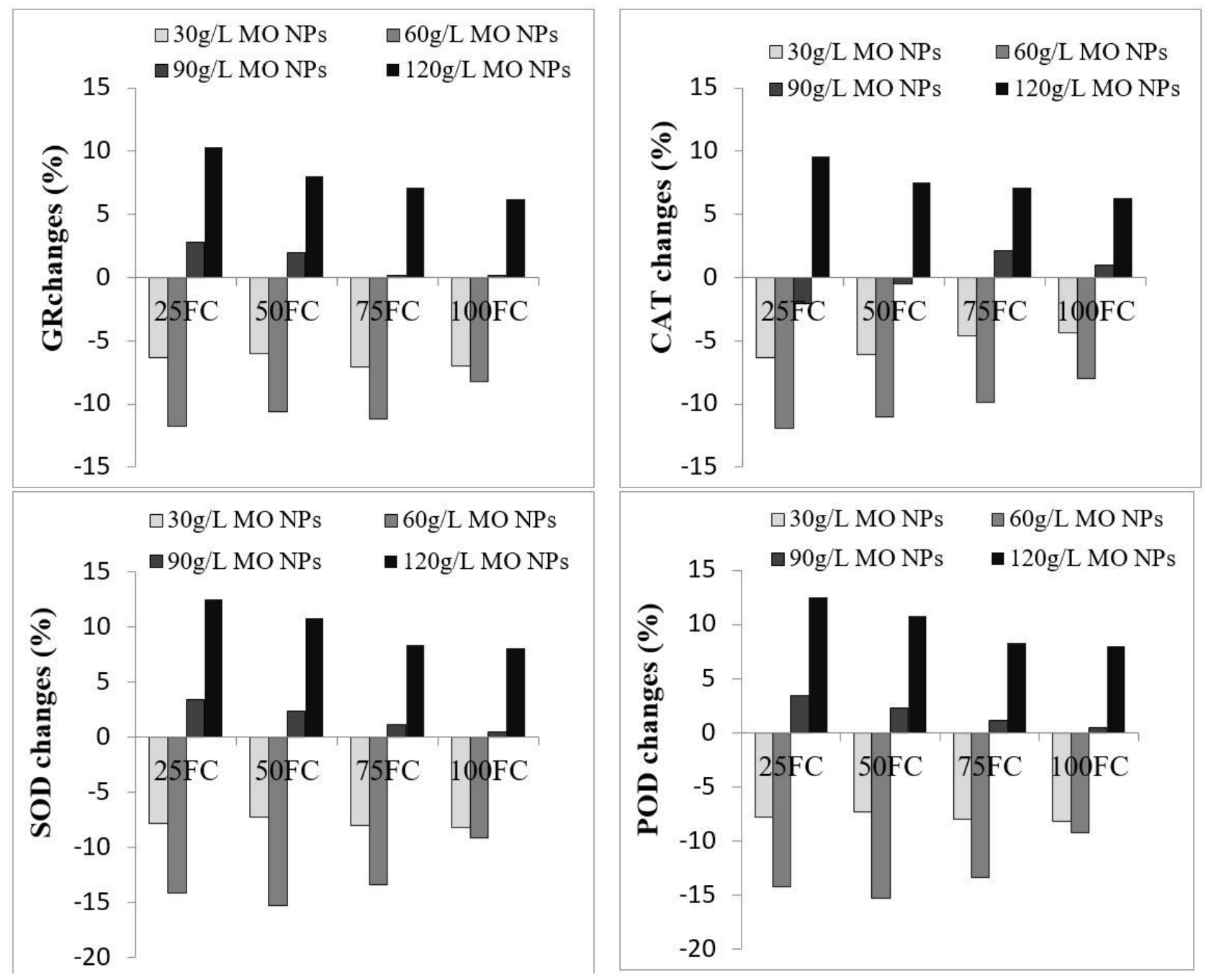

Figure 3

GR, CAT, SOD and POD changes under diferent levels of MO NPs and water stress levels in relation to control. 